\title{
Comparison of Online Sensors for Liquid Phase Hydrogen Sulphide Monitoring in Sewer Systems
}

\author{
Daneish Despot*(D), Micaela Pacheco Fernández and Matthias Barjenbruch
}

Urban Water Management, Technical University of Berlin, Gustav-Meyer-Allee 25, 13355 Berlin, Germany; m.pachecofernandez@tu-berlin.de (M.P.F.); matthias.barjenbruch@tu-berlin.de (M.B.)

* Correspondence: daneish.despot@tu-berlin.de

Citation: Despot, D.; Fernández, M.P.; Barjenbruch, M. Comparison of Online Sensors for Liquid Phase Hydrogen Sulphide Monitoring in Sewer Systems. Water 2021, 13, 1876. https://doi.org/10.3390/w13131876

Academic Editors: Gabriele Freni and Mariacrocetta Sambito

Received: 31 May 2021

Accepted: 3 July 2021

Published: 5 July 2021

Publisher's Note: MDPI stays neutral with regard to jurisdictional claims in published maps and institutional affiliations.

Copyright: (c) 2021 by the authors. Licensee MDPI, Basel, Switzerland. This article is an open access article distributed under the terms and conditions of the Creative Commons Attribution (CC BY) license (https:/ / creativecommons.org/licenses/by/ $4.0 /)$.

\begin{abstract}
Hydrogen sulfide $\left(\mathrm{H}_{2} \mathrm{~S}\right)$ related to wastewater in sewer systems is known for causing significant problems of corrosion and odor nuisance. Sewer systems severely affected by $\mathrm{H}_{2} \mathrm{~S}$ typically rely on online $\mathrm{H}_{2} \mathrm{~S}$ gas sensors for monitoring and control. However, these $\mathrm{H}_{2} \mathrm{~S}$ gas sensors only provide information about the $\mathrm{H}_{2} \mathrm{~S}$ emission potential at the point being monitored, which is sometimes inadequate to design control measures. In this study, a comparison of three market-ready online sensors capable of liquid-phase $\mathrm{H}_{2} \mathrm{~S}$ detection in sewer systems was assessed and compared. Two of the three sensors are based on UV/Vis spectrophotometry, while the other adapted the design and principles of a Clark-type electrochemical microsensor. The $\mathrm{H}_{2} \mathrm{~S}$ measurements of the sensors were statistically compared to a standard laboratory method at first. Following that, the performance of the online sensors was evaluated under realistic sewer conditions using the Berlin Water Company (BWB) research sewer pilot plant. Test applications representing scenarios of typical $\mathrm{H}_{2} \mathrm{~S}$ concentrations found in sulfide-affected sewers and during control measures were simulated. The UV/Vis spectrometers showed that the performance of the sensors was highly dependent on the calibration type and measurements used for deriving the calibration function. The electrochemical sensor showed high sensitivity by responding to alternating anaerobic/anoxic conditions simulated during nitrate dosing. All sensors were prone to measurement disturbances due to high amounts of sanitary solids in wastewater at the study site and required continuous maintenance for reliable measurements. Finally, a summary of the key attributes and limitations of the sensors compared for liquid phase $\mathrm{H}_{2} \mathrm{~S}$ detection is outlined.
\end{abstract}

Keywords: hydrogen sulfide; online sensors; sewer systems; monitoring

\section{Introduction}

Odor and corrosion are two of the major problems associated with sewer systems. These problems are related to the formation of hydrogen sulfide $\left(\mathrm{H}_{2} \mathrm{~S}\right)$ under anaerobic conditions in sewers. Under these conditions, sulfate present in the wastewater is reduced by the sulfate-reducing bacteria (SRB) - primarily residing in the biofilms found on the sewer walls and in sewer sediments producing $\mathrm{H}_{2} \mathrm{~S}$, that diffuse into the flowing wastewater [1,2]. The effects of $\mathrm{H}_{2} \mathrm{~S}$ become noticeable when $\mathrm{H}_{2} \mathrm{~S}$ is transferred from the wastewater (liquid phase) to the sewer atmosphere (gas phase).

In relevance to wastewater systems, $\mathrm{H}_{2} \mathrm{~S}$ exists as a weak acid in the liquid phase that dissociates into bisulfide ( $\mathrm{HS}^{-}$) depending on the sewage $\mathrm{pH}$ [3]. Typically, total dissolved sulfide is used as a sum parameter to represent the amount of $\mathrm{HS}^{-}$and $\mathrm{H}_{2} \mathrm{~S}$ present in the wastewater. Only the molecular form $\left(\mathrm{H}_{2} \mathrm{~S}\right)$ is released to the gas phase, and therefore, is typically used to quantify the extent of the odor and corrosion problems in wastewater systems [3]. The dissociated form $\left(\mathrm{HS}^{-}\right)$is more reactive and participates in key sulfur-related processes generally applied for odor and corrosion control. Therefore, monitoring hydrogen sulfide or its sum parameter total dissolved sulfide $\left(\mathrm{H}_{2} \mathrm{~S}+\mathrm{HS}^{-}\right)$ must be a priority. 
As a common practice in the wastewater industry, liquid phase sulfide measurements are mostly made using classical and standard methods, given the general lack of in-situ sensors. Standard methods introduced in the 1900s and are still widely used today include the iodometric method, methylene-blue method, and the ion-selective electrode method [4]. In the early 2000s, an improved alternative based on ion chromatography was developed for simultaneous determination of Sulfur-species in wastewater [5], and since then, have been widely used in sulfide-related studies in Australia. More recently, a method based on the gas extraction of hydrogen sulfide and subsequent electrochemical detection has been improved and validated as the German Standard for sulfide determination wastewater [6]. However, these standard methods need to be carried offsite and manually in a laboratory. They require preparation of chemical reagents beforehand and sample preparation, which is often time-consuming and involves high manual laboratory effort. In addition, the stability and shelf life of the reagents used for measurements and quality assurance (repeated calibration) are also limited. Furthermore, sulfide is volatile and rapidly oxidizes [5]. Therefore, the sampling procedure and preparation for analytical measurements require great care and precaution. Consequently, classical analytical measurement procedures become overwhelming when the sample size is large, which induces the likeliness of multiple sources of errors [7].

Sensor technologies, such as chalcogenide glass chemical sensors [8], fluorometric optode membrane $[9,10]$, chemiluminescent sensors [11,12], and other chemosensors using microelectrodes like gold amalgam [13] have shown potential for sulfide detection in water. Unfortunately, none of these promising technologies are yet featured as industry-scaled sensors in the wastewater sector for sulfide monitoring in sewer systems. Advances in Ultraviolet-Visible (UV/Vis) spectrophotometry have led to an increased number of spectrometers (spectral sensors) available in the market suitable for sewer sulfide monitoring. Studies using UV/Vis spectrometers developed by manufacturers such as s::can GmbH, Vienna, Austria; GO Systemelektronik GmbH, Kiel, Germany; and TriOS Mess-und Datentechnik GmbH, Oldenburg, Germany, have successfully demonstrated applications of sulfide monitoring in sewer systems [14-16]. More recently, using the principles of electrochemistry, SulfiLogger A/S (Aarhus, Denmark) developed a Clarke-type microelectrochemical sensor scaled for applications in the wastewater sector. Thus far, SulfiLogger A/S has successfully demonstrated several applications, including integrating the sensor as a tool for asset management of sewer systems and demonstrating its capabilities to optimize chemical dosing for sulfide mitigation [17]. The industry-scaled sensors mentioned above can measure in one-minute intervals and provide the opportunity for detailed monitoring of sulfides in sewer systems. In addition, they offer high measurement frequency, real-time detection, spatial flexibility - monitoring at many points, and do not require chemical reagents.

In sulfide-affected sewer systems, conventional chemical dosing agents, such as nitrate and iron salts, are added to control and reduce sulfide occurrence $[18,19]$. To verify the effectiveness of the applied chemical dosing, online $\mathrm{H}_{2} \mathrm{~S}$ gas sensors (e.g., $\mathrm{H}_{2} \mathrm{~S}$-guard, Kemira Oyj, Helsinki, Finland) have been the preferred choice due to the popularity of using $\mathrm{H}_{2} \mathrm{~S}$ gas as an odor marker [20]. Furthermore, $\mathrm{H}_{2} \mathrm{~S}$ gas sensors are simple and relatively easy to install and are not exposed to materials that can cause measurement disturbances. However, $\mathrm{H}_{2} \mathrm{~S}$ gas-phase measurements in some cases are insufficient to prescribe adequate chemical requirements to control sulfide build-up in the studied system. The effects of $\mathrm{H}_{2} \mathrm{~S}$ gas removal by sewer ventilation processes, absorption of $\mathrm{H}_{2} \mathrm{~S}$ on the liquid film at existing material surface, and horizontal gas transport induced by wastewater drag all contribute to lower gas concentrations being detected by the gas sensors and may not represent the actual sulfide problem occurring. Therefore, to gain insight into the actual sulfide levels, liquid-phase $\mathrm{H}_{2} \mathrm{~S}$ or sulfide monitoring is essential. Using liquid phase monitoring, the actual sulfide concentration at the point of interest is determined. This allows the calculation of the required dosage that reduces the sulfide concentration at the point of interest and permits the control at downstream points, which can eventually cause 
problems. Nonetheless, it is important to note that a combination of both gas and liquid phase $\mathrm{H}_{2} \mathrm{~S}$ sensors facilitates an in-depth understanding of the mass transfer and transport of the $\mathrm{H}_{2} \mathrm{~S}$ at the point of monitoring.

Given the importance of liquid phase $\mathrm{H}_{2} \mathrm{~S}$ monitoring in sewers, this study aims to assess three commercial online sensors' performance and evaluate their measurement accuracy and challenges when applied to monitoring sewers symptomatic of severe $\mathrm{H}_{2} \mathrm{~S}$ build-up. More specifically, we determine how comparable measurements of the online sensors (two of which follow UV/Vis spectrometry principles and one based on electrochemistry) are to a standard (reference) method. We further evaluate and compare the sensors' response when deployed in realistic sewer conditions using the Berliner Water Company (BWB) sewer research pilot plant. Finally, we provide an appraisal of the sensors' limitations, challenges, and suitability for developing real-time $\mathrm{H}_{2} \mathrm{~S}$ control systems and sewer asset monitoring and management strategies.

\section{Materials and Methods}

\subsection{Sensors}

The performance of 3 different online sensors was evaluated in this work. For the first part of the investigation, all online sensors were compared to a reference laboratory method (complying with DIN 38405-27:2017-10 [6]) using the $\mathrm{H}_{2} \mathrm{~S}$ Analyzer Cubi (ECH Elektrochemie Halle $\mathrm{GmbH}$, Halle, Germany). A detailed description of the sensors (summary provided in Table 1) and reference methods is provided below:

- Intelligent Spectral Analyzer T4 (ISA, GO Systemelektronik GmbH, Kiel, Germany). The ISA is an in-situ UV/Vis spectrometer that measures the absorbance of various substances in the ultraviolet and visible light range $(200-708 \mathrm{~nm})$ with a $2 \mathrm{~nm}$ resolution. The sensor has an adjustable optical path ranging between 1 and $20 \mathrm{~mm}[15,21]$. For the wastewater application presented in this study, the optical path was set at $1 \mathrm{~mm}$. Automatic cleaning of the sensor is carried out before each measurement using compressed air. As no default or global calibration is provided for the sensor, a local calibration - a site-specific calibration based on the local conditions and wastewater matrix to improve the sensor's accuracy, was carried out beforehand using Multiple Linear Regression (MLR). Detailed information on the calibration process is presented in Pacheco Fernández et al. 2020 [15].

- OPUS (TriOS Mess- und Datentechnik GmbH, Oldenburg, Germany). The OPUS is an ultraviolet (UV) spectral sensor that measures the absorbance of various substances in the UV range. Like the ISA, both sensors are built on the principle of spectrophotometry, which uses light to measure chemical concentrations [22]. The sensor used in the study is portable, lightweight (titanium, $2 \mathrm{~kg}$ ), and has moderate power consumption $(<8 \mathrm{~W})$ [7]. An optical path ranging from 0.3 to $50 \mathrm{~mm}$ is possible; however, given the characteristics of the wastewater used in this study, a path length of $1 \mathrm{~mm}$ was used. The OPUS covers a $200-360 \mathrm{~nm}$ spectral range with a $0.8 \mathrm{~nm}$ resolution utilizing a xenon flash lamp as the light source and a 256-channel high-end miniature spectrometer $[7,23]$. Measurements were set at 1-min intervals with the cleaning function using compressed air, activated every $10 \mathrm{~min}$. To evaluate the plug-and-measure attribute of this sensor, we used the global calibration or predefined configuration provided by the manufacturer for comparison to the other online sensors.

- SulfiLogger ${ }^{T M}$ S1/X1-1020 (SulfiLogger A/S, Aarhus, Denmark). The measurement principle of the SulfiLogger ${ }^{\mathrm{TM}} \mathrm{S} 1 / \mathrm{X} 1-1020$ (here forth referred to as SulfiLogger ${ }^{\mathrm{TM}}$ ) sensor follows the electrochemical detection of $\mathrm{H}_{2} \mathrm{~S} . \mathrm{H}_{2} \mathrm{~S}$ is measured by a current produced when the $\mathrm{H}_{2} \mathrm{~S}$ in the media (liquid or gas phase) penetrates the silicone membrane at the sensor's tip and is subsequently electrochemically oxidized. The sensor is made of stainless steel, lightweight $(0.85 \mathrm{~kg})$, compact, and has a passive anti-fouling flush front [24]. The sensor's $\mathrm{H}_{2} \mathrm{~S}$ measurement range in the liquid phase is $0-5 \mathrm{mg} \mathrm{L}^{-1}$ with a measuring frequency of at least 1-min intervals [24]. Calibration was made 
by mounting the calibration cap to the sensor for a feed of calibration gas with a concentration of $1000 \mathrm{H}_{2} \mathrm{~S}(\mathrm{~g}) \mathrm{ppm}$.

- $\quad$ Reference method using ECH $\mathrm{H}_{2} \mathrm{~S}$ Analyzer Cubi (ECH, Elektrochemie Halle GmbH, Halle, Germany). The reference method complies with the German standards for the determination of sulfide in wastewater (DIN 38405-27:2017-10 [6]). The measuring principle of the $\mathrm{H}_{2} \mathrm{~S}$ Analyzer is based on the gas extraction of $\mathrm{H}_{2} \mathrm{~S}$ from the wastewater sample. This device measures $\mathrm{H}_{2} \mathrm{~S}$ gas with an amperometry sensor, where the sulfide species are first converted into $\mathrm{H}_{2} \mathrm{~S}$ by acidifying the sample with phosphoric acid (4 wt.\%). Before the experiments, we calibrated the device in the measurement range of $0-10 \mathrm{mg} \mathrm{L}^{-1}$ as total dissolved sulfide $\left(\mathrm{DS}_{\mathrm{t}}\right)$, using a standard sulfide stock solution prepared from thioacetamide [6].

Table 1. The liquid phase sensors type, sulfide fractions measured, and measurement range.

\begin{tabular}{|c|c|c|c|}
\hline Sensor & Sensor Type & $\begin{array}{l}\text { Sulfide Species Measured } \\
\text { (Main, (Converted)) }\end{array}$ & $\begin{array}{l}\text { Measurement Range } \\
\left(\mathrm{mg} \mathrm{L}^{-1}\right)\end{array}$ \\
\hline ISA & $\mathrm{UV} /$ Vis spectrometer & $\begin{array}{c}\mathrm{HS}^{-},\left(\mathrm{H}_{2} \mathrm{~S}, \mathrm{DS}_{\mathrm{t}}\right) \\
\text { Dependent on the calibration }\end{array}$ & $\begin{array}{l}\text { Dependent on the reference method used } \\
\text { for calibration } 0-10 \mathrm{DS}_{\mathrm{t}} \mathrm{mg} \mathrm{L}^{-1} \text { (Same as } \\
\text { the reference method used in this study) }\end{array}$ \\
\hline OPUS & UV spectrometer & $\mathrm{HS}^{-},\left(\mathrm{H}_{2} \mathrm{~S}, \mathrm{DS}_{\mathrm{t}}\right)$ & $\begin{array}{l}\text { Dependent on the reference method used } \\
\text { for calibration } \\
\text { Calibration made by the manufacturer }\end{array}$ \\
\hline SulfiLogger ${ }^{\mathrm{TM}}$ & $\begin{array}{l}\text { Micro-electrochemical } \\
\text { (Clark-type) }\end{array}$ & $\mathrm{H}_{2} \mathrm{~S},\left(\mathrm{DS}_{\mathrm{t}}\right)$ & $0-5 \mathrm{H}_{2} \mathrm{~S} \mathrm{mg} \mathrm{L}^{-1}$ \\
\hline
\end{tabular}

$\mathrm{DS}_{\mathrm{t}}$-Total dissolved sulfide.

\subsection{Experimental Site-Sewer Pilot Plant}

Experiments were carried out at a sewer pilot plant located at the pumping station Neukölln II in Berlin, Germany. The layout of the plant includes a feeding pump, an experimental pressure pipe, and a gravity pipe (Figure 1). The slope of the gravity pipe is fixed at a $1.18 \%$ incline with a filling level set at $17.5 \%$ through a lock. The lock ensured that the sensors were submerged and measured in the liquid phase. Using predefined pumping cycles, wastewater from the pump station was fed to the experimental lines during the investigation. An overview of the cycles and their related hydraulic retention time is provided in Figure S1. All 3 online sensors were installed in the gravity pipe next to sampling point A. Furthermore, $\mathrm{pH}$ (Kuntze Instruments $\mathrm{GmbH}$, Meerbusch, Germany) and temperature (Easytemp TSM487, Endress + Hauser, Reinach BL, Switzerland) were monitored using the Water Measuring Line (WML) connected to the gravity sewer.

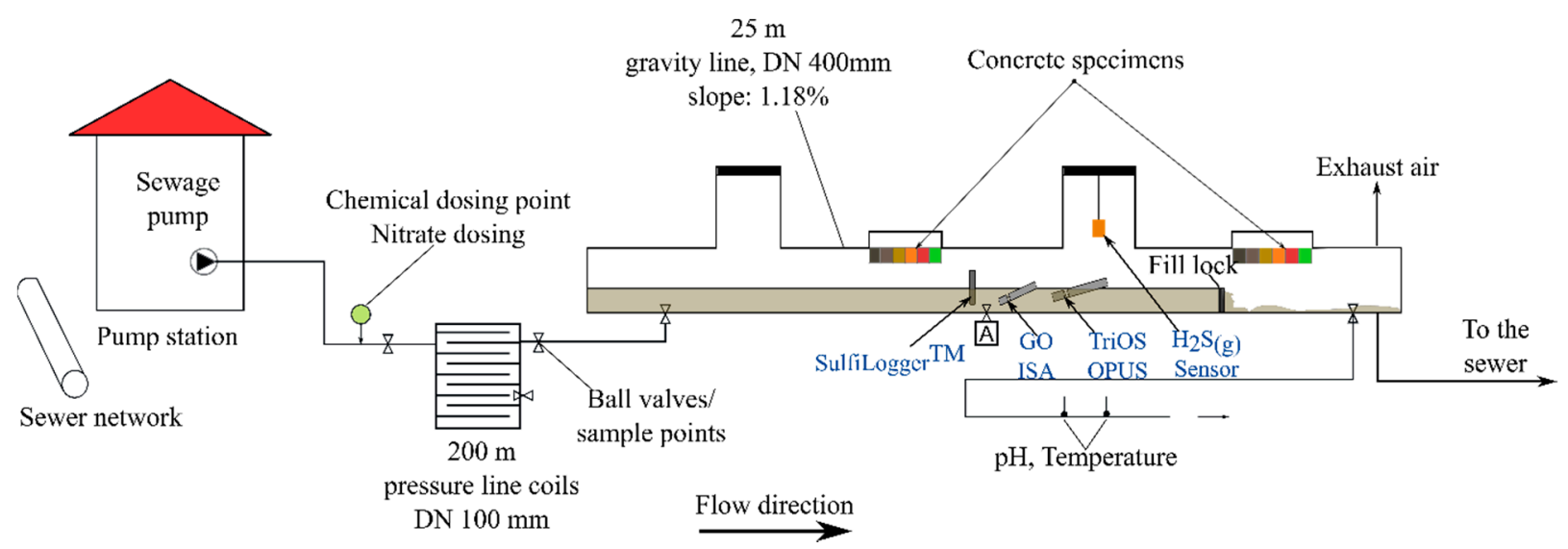

Figure 1. Schematic layout of the Berlin Water Company Research Sewer Pilot Plant (RSPP). The sensors evaluated are in blue. Wastewater samples collected for comparison withdrawn at ball-valve (A). 


\subsection{Sulfide Equilibrium in Water}

Three sulfide species are usually present in wastewater: sulfide ions $\left(\mathrm{S}^{2-}\right)$, bisulphide $\left(\mathrm{HS}^{-}\right)$, and hydrogen sulfide $\left(\mathrm{H}_{2} \mathrm{~S}\right)$. The sum parameter for all 3 species is total dissolved sulfide (Equation (2)). The equilibrium of all species at $20^{\circ} \mathrm{C}$ is described by Yongsiri et al. 2004 [25] (see Equation (1)).

$$
\begin{gathered}
\mathrm{S}^{2-}+2 \mathrm{H}^{+} \stackrel{K_{a 2} \approx 0.8 \cdot 10^{-17}}{\longrightarrow} \mathrm{H}^{+}+\mathrm{HS}^{-} \stackrel{K_{a 1} \approx 1 \cdot 0 \cdot 10^{-7}}{\longrightarrow} \mathrm{H}_{2} \mathrm{~S}_{(\mathrm{aq})} \\
{\left[D S_{t}\right]=\left[\mathrm{H}_{2} \mathrm{~S}\right]+\left[\mathrm{HS}^{-}\right]+\left[\mathrm{S}^{2-}\right]}
\end{gathered}
$$

The sensors presented in this work measure different sulfide species. The SulfiLogger ${ }^{\mathrm{TM}}$ measures $\mathrm{H}_{2} \mathrm{~S}$ directly, while the OPUS and ISA directly measure $\mathrm{HS}^{-}$based on its absorbance in the $\mathrm{UV}$ range. As $\mathrm{HS}^{-}$and $\mathrm{H}_{2} \mathrm{~S}$ exist in an equilibrium that is $\mathrm{pH}$-dependent [10], $\mathrm{H}_{2} \mathrm{~S}$ and total dissolved sulfide are indirectly measured. Besides using $\mathrm{HS}^{-}$as a proxy, the ISA also directly measured $\mathrm{H}_{2} \mathrm{~S}$ and total dissolved sulfide based on the MLR calibration algorithm. The reference method $(\mathrm{ECH})$ measures the total dissolved sulfide content in the sample as hydrogen sulfide.

To provide a homogeneous comparison, we selected hydrogen sulfide as a standard parameter. Therefore, all measurements were converted into hydrogen sulfide according to the chemical equilibrium reactions of multiple proton acids presented in Equations (3) and (4). The $K_{a 2}$-the second dissociation constant based on the deprotonation of $\mathrm{HS}^{-}$presented in Equations (3) and (4) can be neglected for domestic wastewater because of its low value, which indicates that sulfide ions are only present in insignificant amounts [25-27]. The negative logarithms of the equilibrium constants (Equations (4) and (5)) were computed according to $[28,29]$ :

$$
\begin{gathered}
{\left[\mathrm{H}_{2} \mathrm{~S}\right]=\frac{D S_{t}}{1+\frac{K_{a 1}}{\left[\mathrm{H}^{+}\right]}+\frac{K_{a 1} \cdot K_{a 2}}{\left[\mathrm{H}^{+}\right]^{2}}}} \\
{\left[\mathrm{H}_{2} \mathrm{~S}\right]=\left[\mathrm{HS}^{-}\right] \cdot \frac{\frac{\left[\mathrm{H}^{+}\right]}{K_{a 1}}+1+\frac{K_{a 2}}{\left[\mathrm{H}^{+}\right]}}{1+\frac{K_{a 1}}{\left[\mathrm{H}^{+}\right]}+\frac{K_{a 1} \cdot K_{a 2}}{\left[\mathrm{H}^{+}\right]^{2}}}} \\
p K_{1}=-98.080+\frac{5765.4}{T}+15.0455 \times \ln (T)
\end{gathered}
$$

where $D S_{t}$ is the total dissolved sulfide concentration (in $\mathrm{mol} \mathrm{L}^{-1}$ ), $K_{a 1}$ and $K_{a 2}$ are equilibrium constants, $p K_{\mathrm{a} 1}$ and $p K_{\mathrm{a} 2}$ are negative logarithms of the equilibrium constants, and $T$ is the temperature (in $\mathrm{K}$ ).

\subsection{Experimental Conditions}

The experiments for comparing the sensors were carried out in 2 phases. In phase 1 of the experiments, we compared the measurements of the manual sample using the reference method (DIN 38405-27:2017-10 [6]) to the measurements of the online sensors. In phase 2, 3 test applications were performed under different sewage conditions using the BWB sewer pilot plant to evaluate and assess the performance of the sensors. For the first 2 test applications, we evaluated the influence of wastewater pump operation on $\mathrm{H}_{2} \mathrm{~S}$ production. These tests were made using wastewater from the pump station that was not dosed with chemicals, to suppress $\mathrm{H}_{2} \mathrm{~S}$ formation in the experimental pressure sewer. As for the final test application, we dosed calcium nitrate at the inlet of the pressure sewer as a measure for suppressing $\mathrm{H}_{2} \mathrm{~S}$ formation. During phase 2 of the experiment, we focused more on ensuring that the 3 sensors were adequately maintained to minimize measurement disturbances. Consequently, no manual samples were taken for comparison with the reference method. Despite not using the reference method for comparison, we frequently calibrated the SulfiLogger ${ }^{\mathrm{TM}}$ (one per week and each time before a new trial) 
during test applications as a guide for quality assurance. Table 2 provides an overview of the 3 test applications. An explanation of the applied dosing strategy is in Section 2.6.

Table 2. Summary of the test applications made in phase 2 of the study to test the performance of online sensors under realistic sewer conditions.

\begin{tabular}{|c|c|c|}
\hline Test Application & Aim & Key Interest \\
\hline (1) Intermittent flow & $\begin{array}{c}\text { To determine sensors' ability } \\
\text { to detect } \mathrm{H}_{2} \mathrm{~S} \text { in an } \\
\text { intermittently operated } \\
\text { pressure sewer. } \\
\text { To establish baseline } \\
\text { conditions, i.e., when no } \mathrm{H}_{2} \mathrm{~S} \\
\text { control measures are } \\
\text { implemented. }\end{array}$ & $\begin{array}{l}\text { Diurnal sulfide profiles-daily } \\
\text { variation and influence of } \\
\text { other key parameters, e.g., } \\
\text { residence time, soluble COD. }\end{array}$ \\
\hline (3) Calcium nitrate dosing & $\begin{array}{l}\text { To determine the sensors' } \\
\text { response during the } \\
\text { continuous operation of the } \\
\text { wastewater pump under } \\
\text { normal wastewater } \\
\text { conditions. }\end{array}$ & $\begin{array}{l}\text { Sulfide levels for a case where } \\
\text { longer pumping periods are } \\
\text { used instead of shorter } \\
\text { intermittent } \\
\text { intervals-influence of } \\
\text { pumping interval on sulfide } \\
\text { production. } \\
\text { Anoxic sulfide oxidation, the } \\
\text { impact of varying nitrate } \\
\text { concentration, } \\
\text { effect of pH increase due to } \\
\text { denitrification on sulfide } \\
\text { detection. }\end{array}$ \\
\hline
\end{tabular}

\subsection{Sampling, Laboratory Analysis, and Data Collection}

For phase 1, manual samples were collected across 6 days of monitoring at ball-valve A (Figure 1). Sample collection was conducted during the morning and evening periods and only during the wastewater pumping periods, set to $7 \mathrm{~min}$. The preparation and preservation of the samples were made on-site. The $\mathrm{pH}$ and temperature of the manual samples were immediately recorded using the HQ11D Portable $\mathrm{pH}$ Meter (Hach Lange $\mathrm{GmbH}$, Düsseldorf, Germany). Preparation of the samples for total dissolved sulfide using the reference method included the separation of particulate matter from the sample by flocculation with sodium hydroxide $(\mathrm{NaOH})$ and aluminum chloride $\left(\mathrm{AlCl}_{3}\right)$ and subsequent settling [4]. To preserve the samples, we added zinc acetate $(0.4 \mathrm{~mL} 1 \mathrm{M}$ per $100 \mathrm{~mL}$ of sample) to the prepared sample, which was then cooled to $4{ }^{\circ} \mathrm{C}$ and stored until analyzed.

All manual samples taken for comparison were analyzed in the laboratory using the $\mathrm{H}_{2} \mathrm{~S}$ Analyzer Cubi within 2-3 days after sampling. In addition, all sulfide measurements were made in duplicates - two subsamples from the samples prepared on-site. To determine whether the samples should qualify for comparative analysis or be classified as outliers, we calculated the difference between duplicates and determined the $95 \%$ confidence interval [30]. The samples that fell outside the 95\% confidence interval were further examined by inspecting the plots of the $\mathrm{ECH}$ sensor response ( $\mathrm{mV}$ vs. time) curves used to calculate the final total dissolved sulfide concentration. In addition, we inspected the metadata regarding the sample measurement, e.g., dilution factor, time of sampling, and operating conditions of the pilot plant.

Since sensors were placed approximately $30 \mathrm{~cm}$ apart from each other and all sensors did not directly measure the sample volume withdrawn for analysis, we took the median of the measurements during the operating (pump on) period of the wastewater pump. This was done to account for the spatial and temporal differences in measurements of the sensors. Finally, we combined the median measurements of the sensors during flow periods (wastewater pump switched on), the $\mathrm{pH}$, and temperature to form the comparison data set. 


\subsection{Chemical Dosing Scheme}

Given the widespread use of calcium nitrate $\left(\mathrm{Ca}\left(\mathrm{NO}_{3}\right)_{2}\right)$ for sulfide control in sewer systems, conducting trials with varying nitrate concentrations were used to test the sensors' performance under anoxic conditions. The addition of $\mathrm{Ca}\left(\mathrm{NO}_{3}\right)_{2}$ promotes anoxic sulfide oxidation and competitive exclusion of sulfate-reducing bacteria (SRB) [18]. During nitrate dosing, an increase in sewage $\mathrm{pH}$ is expected due to heterotrophic denitrification and anoxic sulfide oxidation, permitting the opportunity to examine the sensors' response to detecting sulfide at $\mathrm{pH}$ values above $8 . \mathrm{Ca}\left(\mathrm{NO}_{3}\right)_{2}$ was injected at the beginning of the experimental pressure sewer, which is then conveyed to the gravity sewer (Figure 1). A flow proportional nitrate dosage in concentrations of $7.5,14$, and $28 \mathrm{mg}-\mathrm{N} \mathrm{L}^{-1}$ was used to simulate limited, optimal, and overdosage scenarios. Limited dosage describes a scenario where minimum chemical requirements are supplied to achieve partial $\mathrm{H}_{2} \mathrm{~S}$ control, with an expected resumption of sulfate reduction once the nitrate added is consumed. The optimal dosage in this study is defined as the minimum chemical requirements to achieve a complete $\mathrm{H}_{2} \mathrm{~S}$ suppression throughout the chemical dosing period. Overdosages refers to an excessive amount of chemical to achieve complete $\mathrm{H}_{2} \mathrm{~S}$ suppression.

\subsection{Assessment and Statistical Analysis for Comparison of Sensors}

Using the comparison data set (Section 2.5), we performed basic statistical measures that are widely used and accepted for data comparison following Borrego et al. 2016 [31]. These measures are presented in the supplementary material (Table S1) and include Pearson's Coefficient, Concordance Correlation Coefficient (CCC), Mean Bias (MB), Root Mean Square Difference (RMSD) and Unbiased Root Mean Square Difference (uRMSD). To visualize the relationship and agreement between the measurement pairs (sensor and reference measurements), we plotted correlation and Bland-Altman plots. In addition, we constructed a target diagram following Jolliff et al. 2009 [32] to provide summary information about how the pattern statistics (unbiased RMSD) and the bias (difference of mean values) each contribute to the magnitude of the total Root-Mean-Square Difference (RMSD) of the measurement pairs. Finally, we applied the non-parametric Friedman test to assess whether there are any statistically significant differences between the distributions of the measurements (all measurements, including the reference measurements). This test was then followed by a post-hoc analysis (pairwise comparisons) based on the Wilcoxon signedrank test to identify which pairs of measurement groups are different. A brief description of the analysis introduced above is provided in the supplementary material.

To compare the $\mathrm{H}_{2} \mathrm{~S}$ measurements obtained during the test application, we performed standard statistical measures on the $\mathrm{H}_{2} \mathrm{~S}$ time series of the sensors. This includes the median, median absolute deviation (MAD), and range. For the trials employing intermittent wastewater pump operation (1st \& 3 rd test applications), we divided the $\mathrm{H}_{2} \mathrm{~S}$ measurements into periods of flow (pump on) and no-flow (pump off) to assess the sensors' response during those periods. To evaluate the performance under dosing conditions, we calculated the removal percentages using Equation (S2), in which the median $\mathrm{H}_{2} \mathrm{~S}$ concentrations obtained during baseline (test application 1) and dosing trials were used.

All data handling and statistical analysis were carried out using Python (Python Software Foundation. Python Language Reference, version 3.7. Available at http:/ / www. python.org, accessed on 25 May 2021). In particular, the python MethComp [33] package was modified and used for the correlation and Bland-Altman plots. The SkillMetrics [34] package was used for plotting the target diagram. All other computations and statistical analyses were made using pandas [35,36], NumPy [37], statsmodel, scikit learn [38,39]. As for the visualization, figures were created with the Matplotlib [40] and seaborn [41] libraries.

\section{Results and Discussion}

\subsection{Comparison of Sensors to the Reference Method (Phase 1)}

For phase 1 of the experiment, $\mathrm{H}_{2} \mathrm{~S}$ measurements of 22 samples measured using the reference method were used to compare the measurements from the online sensors. 
The temperature of the samples collected were $19.5 \pm 0.6^{\circ} \mathrm{C}$ (median \pm MAD), while the $\mathrm{pH}$ was $7.4 \pm 0.3 \mathrm{pH}$ units, varying from 6.9 to $8 \mathrm{pH}$ units. Correlation analysis provides an insight into how strongly the measurement pairs are related [42]. In this study, Pearson's correlation coefficient $(r)$ and the regression functions were used to evaluate the linear association between the sensor and reference measurements. The regression lines in Figure 2a-c all show a relatively strong linear trend with the correlation coefficient values above 0.87 when considering the entire measurement range of the reference method $(\mathrm{ECH})$. At a closer look, we observed that for all three comparison pairs (ECH vs. ISA, ECH vs. OPUS, and ECH vs. SulfiLogger ${ }^{\mathrm{TM}}$ ), the $\mathrm{H}_{2} \mathrm{~S}$ reference measurement range influenced the correlation coefficient. For $\mathrm{H}_{2} \mathrm{~S}$ concentrations $>5 \mathrm{mg} \mathrm{L}^{-1}$, stronger correlations $(\mathrm{r}=0.89$, $0.92,0.85)$ were found when compared to concentrations $\leq 5 \mathrm{mg} \mathrm{L}^{-1}(\mathrm{r}=0.74,0.65,0.10)$ (Table S2).

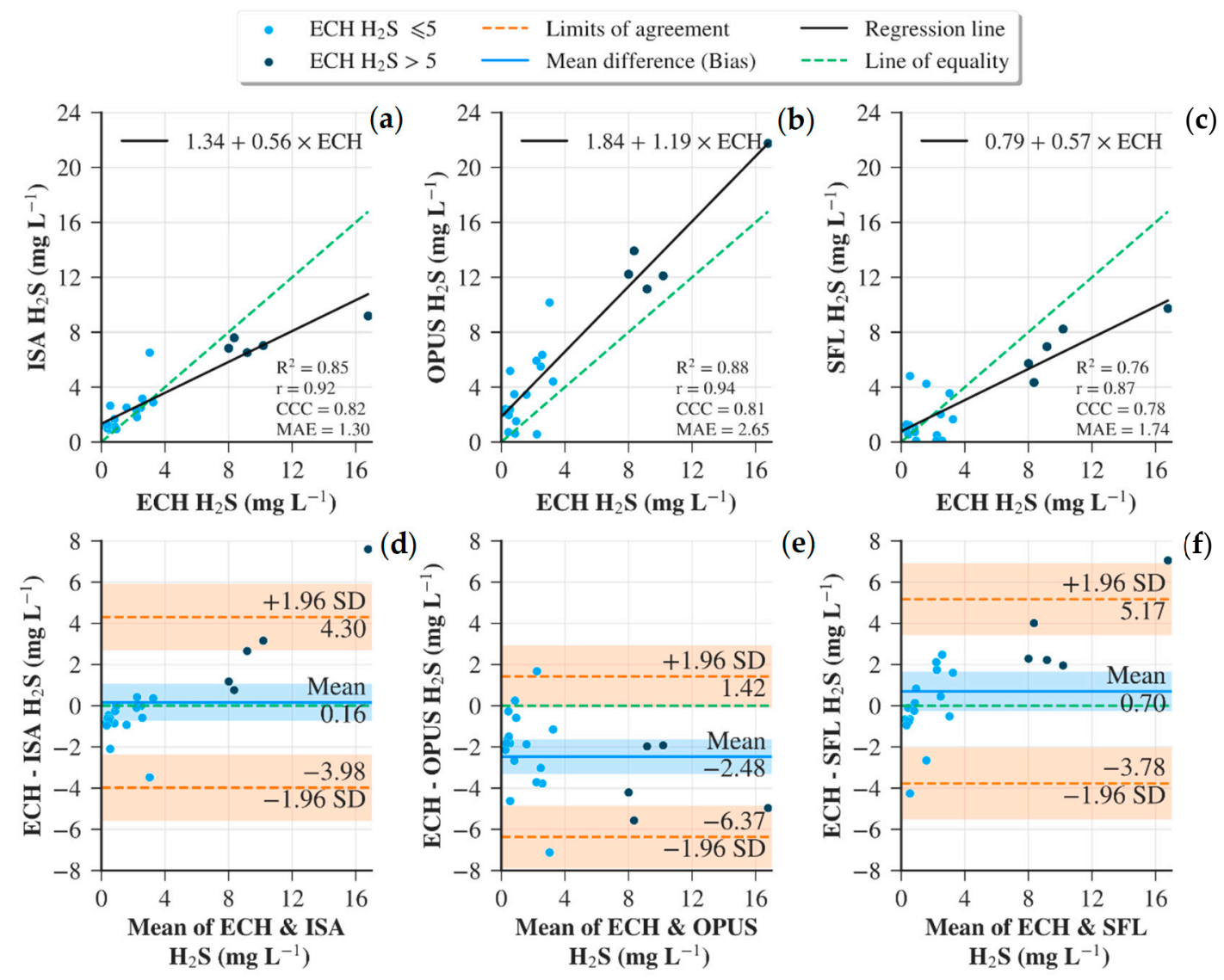

Figure 2. Correlation plots between the reference (ECH) and sensors' (ISA, OPUS, and SulfiLogger ${ }^{\mathrm{TM}}$ (SLF)) measurements $(\mathbf{a}-\mathbf{c})$. Bland-Altman plots for comparison pair (ECH vs. ISA, ECH vs. OPUS, and ECH vs. SLF) (d-f). The $x$-axis shows the mean of the reference and sensor measurement. The $y$-axis corresponds to the difference between the reference and sensor measurement.

Since Pearson's correlation coefficient ( $\mathrm{r}$ ) only provides a measure that quantifies the degree to which measurement pairs are related and conforms to the regression line (best fit) [43], we used the concordance correlation coefficient (CCC) to provide a measure of reproducibility. CCC assesses how close the data points are to the best fit and evaluates the extent to which they fall on the line of equality. The CCC values for each comparison pair were in a similar range of $0.79-0.82$. According to the descriptive scale suggested by McBride 2005 [44] for continuous variables, CCC values less than 0.9 have a poor strength of agreement, suggesting that none of the sensors produced identical measurements to the reference method. 
The ISA and SulfiLogger ${ }^{\mathrm{TM}}$ showed a similar mean absolute error $(\mathrm{MAE}=1.30$ \& $1.70 \mathrm{mg} \mathrm{L}^{-1}$ ) and Root Mean Square Difference (RMSD = $2.12 \& 2.39 \mathrm{mg} \mathrm{L}^{-1}$ ) values and were considerably lower than the OPUS (MAE $=2.65 \mathrm{mg} \mathrm{L}^{-1}, \mathrm{RMSD}=3.18 \mathrm{mg} \mathrm{L}^{-1}$ ) (Table S2). Contrary to the correlation for reference measurements $>5 \mathrm{mg} \mathrm{L}^{-1}$, both MAE and RMSD showed a much smaller spread at the lower concentration range. The smaller MAE and RSMD at the lower measurement range indicate that both ISA and SFL have a closer agreement to reference measurements at $\mathrm{H}_{2} \mathrm{~S}$ concentrations $<5 \mathrm{mg} \mathrm{L}^{-1}$ despite having a lower correlation coefficient.

The Bland-Altman plots in Figure $2 \mathrm{~d}-\mathrm{f}$ quantifies the mean bias (mean difference between the reference and sensor measurement) and the limits of agreement (95\% limits). The bias of comparison pairs revealed that the ISA measurements were the closest to the reference measurements with a mean difference of $0.16 \mathrm{mg} \mathrm{L}^{-1}$. The positive value here means that, on average, the ISA is $0.16 \mathrm{mg} \mathrm{L}^{-1}$ less than the reference method. Similarly, on average, the SulfiLogger ${ }^{\mathrm{TM}}$ measured $0.70 \mathrm{mg} \mathrm{L}^{-1}$ less than the ECH. On the other hand, the OPUS measurements were consistently higher than the ECH measurement, with a mean difference of $-2.48 \mathrm{mg} \mathrm{L}^{-1}$, showing a much significant deviation to the reference method compared to the other sensors. The limits of agreement for all three comparison pairs resulted in wide ranges (dashed-orange lines in Figure $2 \mathrm{~d}-\mathrm{f}$ ). For example, $95 \%$ of the samples measured by the ISA would be 3.98 less and $4.30 \mathrm{mg} \mathrm{L}^{-1}$ higher than the ECH measurement, which is unacceptable. Ideally, values narrowly distributed around a mean difference of zero are preferred. By defining a priori limits of maximum acceptable differences of $\pm 1 \mathrm{mg} \mathrm{L}^{-1}$ (a narrow interval), we found that $73 \%$ of the ECH-ISA measurement pairs fell in the range $\pm 1 \mathrm{mg} \mathrm{L}^{-1}$. In contrast, for the ECH-SulfiLogger ${ }^{\mathrm{TM}}$ and ECH-OPUS, only 50\%, and 14\% fell in that range.

Applying the non-parametric Freidman test showed significant differences between the $\mathrm{H}_{2} \mathrm{~S}$ measurements obtained from the sensors and the reference method (Chi-square $\left.\left(\chi^{2}\right)=27, p \ll 0.001\right)$. However, the post-hoc pairwise Wilcoxon signed-rank test revealed that only the comparison pairs involving the OPUS were significantly different $(p<0.001)$, confirming an agreement between the reference method and both ISA and SulfiLogger ${ }^{\mathrm{TM}}$. The relatively close markers of the ISA and SulfiLogger ${ }^{\mathrm{TM}}$ and the shorter distance to the true marker on the target diagram (Figure S2) further support that the ISA and SulfiLogger ${ }^{\mathrm{TM}}$ were of similar accuracy when compared to the OPUS. Despite the possibilities of sampling and measurement errors, we conclude that both the ISA and SulfiLogger ${ }^{\mathrm{TM}}$ showed a good agreement with the reference method.

The calibration function of the ISA was derived using measurements made from the reference method prior to the start of this study. Given the result of having the lowest mean bias, we presume that the relationship of the reference method to the calibration function used for predicting the $\mathrm{H}_{2} \mathrm{~S}$ concentration may have influenced the strong agreement compared to the other sensors. The lack of agreement between the OPUS and reference measurements indicates that the default setting (global calibration) overestimates the $\mathrm{H}_{2} \mathrm{~S}$ concentration and is therefore inadequate. Performing a local calibration to fine-tune and adjust the sensor to the conditions and wastewater matrix in the study location will improve its $\mathrm{H}_{2} \mathrm{~S}$ detection. Several studies demonstrate improvement in the sensors' accuracy by applying a local calibration [45-47], which infers the necessity of locally calibrating UV/Vis optical sensors for reliable measurements.

To account for and explain the deviation of the sensors' measurements from the reference measurements, one must consider the possible errors during sampling, sample preparation, and measurement. For example, we only used zinc acetate to preserve the manual samples taken for comparison and excluded sodium hydroxide $(\mathrm{NaOH})$, since it resulted in precipitates that affected the measurement. Several studies on sulfide-related processes have opted for only using zinc acetate for sample preservation and have proven that the method is robust and consistent [48,49]. However, by leaving out the $\mathrm{NaOH}$, unremoved bacteria present in the sample could have altered the sulfide concentration during storage. 
Another possible error that could have contributed to the difference between reference and sensor measurement could be during the conversion of bisulfide and total dissolved sulfide to hydrogen sulfide. The conversion process is dependent on the $\mathrm{pH}$, and therefore, accurate and reliable $\mathrm{pH}$ measurements are required. Finally, it is important to note that the sensors did not directly measure that sample withdrawn for analysis using the reference method, but instead measured its parenting wastewater parcel. This indirect sample comparison is likely to also contribute to the differences between the reference measurement and sensor.

\subsection{Sensors' Performance under Different Wastewater Pump Operation (Phase 2)}

The diurnal $\mathrm{H}_{2} \mathrm{~S}$ profiles in Figure 3a demonstrate the influence of the intermittent operation of the experimental pressure sewer. The grey lines in Figure 3a mark the wastewater pumping events, set to $7 \mathrm{~min}$ throughout the experiment. For most pump events, the sensors responded similarly-a sharp increase in $\mathrm{H}_{2} \mathrm{~S}$ concentration, which monotonically decreased during the periods with no flow through the experimental gravity sewer. The $\mathrm{H}_{2} \mathrm{~S}$ profiles of the ISA sensor were much lower compared to the OPUS and SulfiLogger ${ }^{\mathrm{TM}}$, measuring an $\mathrm{H}_{2} \mathrm{~S}$ concentration of $3.42 \pm 0.77 \mathrm{mg} \mathrm{L}^{-1}$ (median $\pm \mathrm{MAD}$ ), as compared to $6.61 \pm 1.78$ and $5.37 \pm 1.29 \mathrm{mg} \mathrm{L}^{-1}$, respectively. All three sensors show that the highest $\mathrm{H}_{2} \mathrm{~S}$ concentrations were typically found for wastewater parcels discharging the pressure sewer between 8:00 and 12:00. The wastewater exiting the pressure sewer at 8:00 (residence time, $\mathrm{RT}=7 \mathrm{~h})$ and 10:00 $(\mathrm{RT}=8 \mathrm{~h})$, the highest residence times used in the study, are associated with observed high $\mathrm{H}_{2} \mathrm{~S}$ concentrations. In addition, the wastewater slugs entering the pressure sewer at 8:00 and 10:00 had higher sulfide and COD concentrations, which are believed to have contributed to the typically high $\mathrm{H}_{2} \mathrm{~S}$ concentrations when subsequently discharged at 11:00 and 12:00 $\mathrm{h}$.

(a)

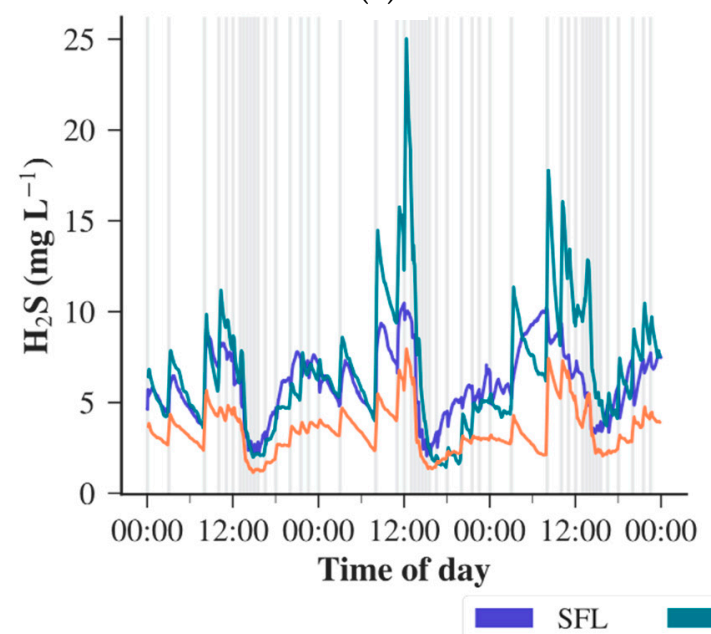

(b)

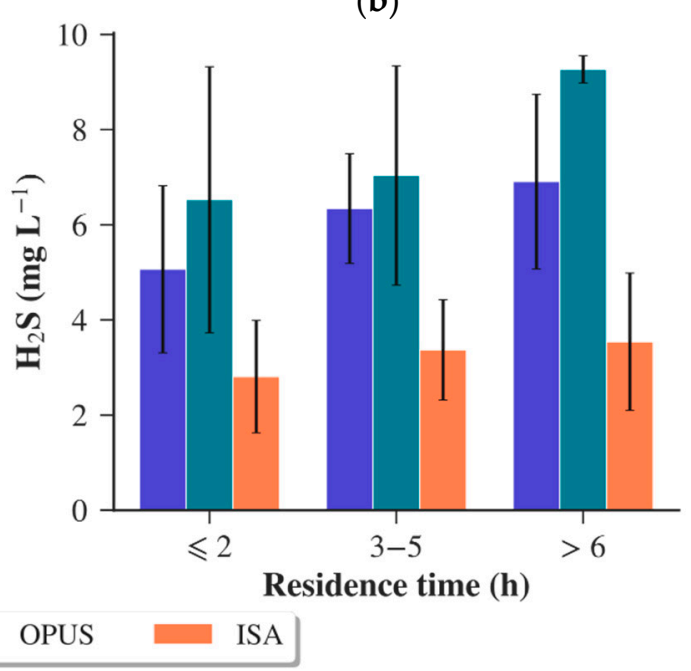

Figure 3. Diurnal hydrogen sulfide profiles during intermittent wastewater pump operation (a). Influence of the residence time on the $\mathrm{H}_{2} \mathrm{~S}$ concentration (b). Error bars show the standard deviation of the mean $\mathrm{H}_{2} \mathrm{~S}$ concentration for each residence time group $(\leq 2 \mathrm{~h}, 3-5 \mathrm{~h} \&>6 \mathrm{~h})$.

Figure $3 \mathrm{~b}$ further demonstrates the influence of the residence times on the sulfide concentration discharged from the pressure sewer. It shows that all three sensors responded similarly, with the OPUS recording the highest $\mathrm{H}_{2} \mathrm{~S}$ concentrations for all residence time groups. The results indicate that all three sensors were able to showcase comparable diurnal patterns and a linear increase with increasing residence times, with the ISA recording much lower $\mathrm{H}_{2} \mathrm{~S}$ concentrations.

The comparison of the sensors under different wastewater pumping operations is shown in Figure 4. Figure 4a demonstrates the distribution of the $\mathrm{H}_{2} \mathrm{~S}$ concentration 
during the flow (pump switched on) and no flow (pump switched off). Comparing the distributions of $\mathrm{H}_{2} \mathrm{~S}$ measurements between the flow and no-flow periods indicated that all sensors detected similar distributions for these flow periods. The SulfiLogger ${ }^{\mathrm{TM}}$ and OPUS recorded similar median $\mathrm{H}_{2} \mathrm{~S}$ concentrations (5.94 and $6.13 \mathrm{mg} \mathrm{L}^{-1}$, respectively), while the median $\mathrm{H}_{2} \mathrm{~S}$ concentration of the ISA $\left(3.23 \mathrm{mg} \mathrm{L}^{-1}\right)$ was significantly lower (white dots in Figure 4a).
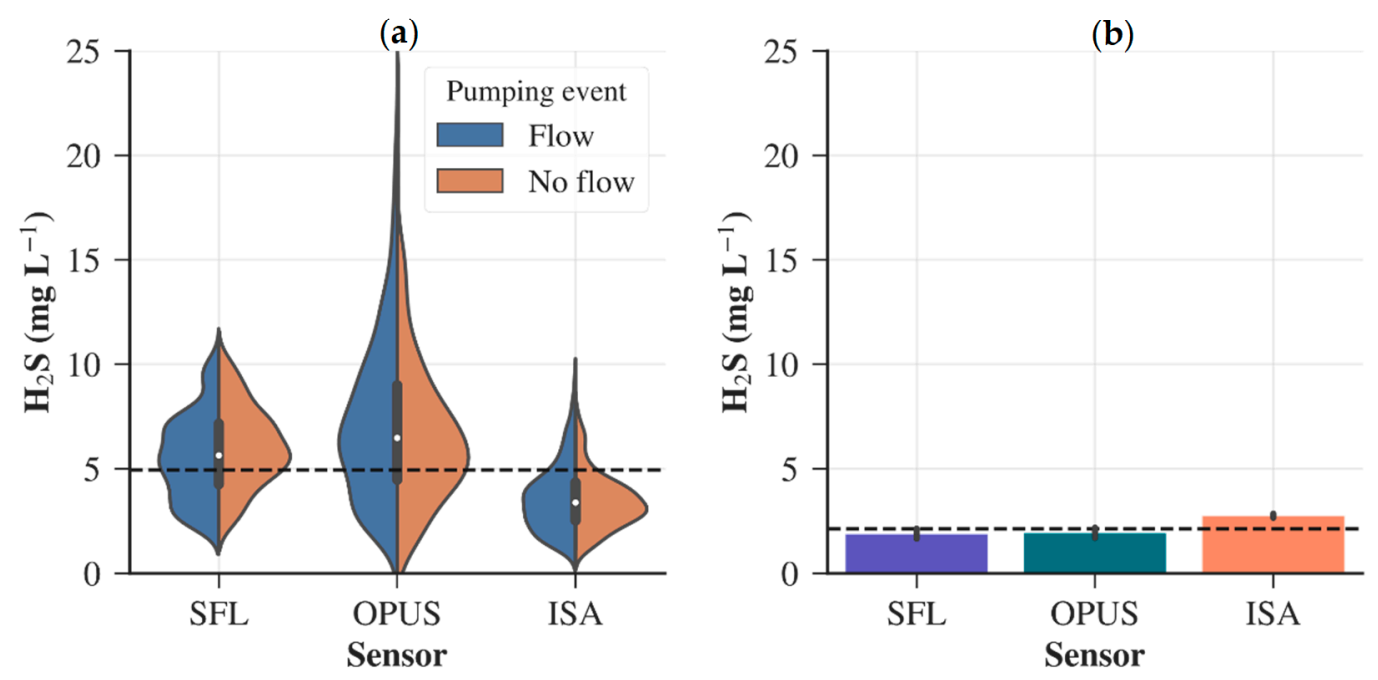

Figure 4. Comparison of the sensors under different flow conditions. Violin plots (combination of boxplots and density trace plots) comparing the median $\mathrm{H}_{2} \mathrm{~S}$ concentration measured by the sensors during the switched on $(\square)$ and off ( $\square$ ) periods of the intermittent scenario (a). Barplots comparing the median $\mathrm{H}_{2} \mathrm{~S}$ measurements of the sensors during constant flow scenario (b). The dashed lines (-) mark the mean $\mathrm{H}_{2} \mathrm{~S}$ recorded by the sensors for the different wastewater operation.

In an intermittently-operated pressure sewer, sulfide production mostly occurs during and immediately following a pumping event, as the active mixing re-establishes substrate availability and enhances mass transfer at the biofilm-liquid interface $[16,50]$. Therefore, intermittently-operated pressure sewers with a frequent pumping activity are likely to have more sulfide problems than those with fewer and longer pumping events. During the intermittent operation, the $\mathrm{H}_{2} \mathrm{~S}$ concentrations detected by the sensors were 3.23, 3.30, and 1.27 times higher than the median measurements recorded during the constant flow operation (Figure $4 \mathrm{~b}$ ) for the SulfiLogger ${ }^{\mathrm{TM}}$, OPUS, and ISA, respectively. Thus, the higher $\mathrm{H}_{2} \mathrm{~S}$ measurements during the intermittent operation confirmed that pumping frequency affects the sulfide produced in pressure sewers. Furthermore, by comparing the average $\mathrm{H}_{2} \mathrm{~S}$ concentration obtained under the different pump operations (intermittent vs. constant), we observed that reducing the pumping frequency provides an opportunity to reduce mean daily sulfide production. Similar findings were presented in Shypanski et al. 2018 [50], highlighting the influence of pumping frequency on sulfide production in sewers and the possibility to optimize the wastewater pumping operation to reduce the daily sulfide production once additional storage capacity is available.

\subsection{Performance of Sensors during Nitrate Dosing}

Figure 5a-c displays the hydrogen sulfide $\left(\mathrm{H}_{2} \mathrm{~S}\right)$ profiles obtained during nitrate dosing. For the applied nitrate dosages of 7.5 (limited), 14 (optimal), and $28 \mathrm{mg}-\mathrm{N} \mathrm{L}^{-1}$ (overdosing), the SulfiLogger ${ }^{\mathrm{TM}}$ (SLF) and OPUS showed similar $\mathrm{H}_{2} \mathrm{~S}$ profiles. In comparison, the ISA only showed a similar pattern during the overdosing scenario. During the overdosing scenario, all sensors showed $>98 \% \mathrm{H}_{2} \mathrm{~S}$ removal (Figure $5 \mathrm{~d}$ ). For the limited and optimal scenarios, both SulfiLogger ${ }^{\mathrm{TM}}$ (SLF) and OPUS demonstrated $\mathrm{H}_{2} \mathrm{~S}$ removal efficiencies above $93 \%$; however, $<36 \%$ removal was calculated using the ISA measurements. We observed that the SulfiLogger ${ }^{\mathrm{TM}}$ detected a re-emergence of sulfide production during the limited dosing scenario when the residual nitrate concentration dropped below $5 \mathrm{mg} \mathrm{N} \mathrm{L}^{-1}$. 
The increasing sulfide concentration indicates the resumption of sulfide-producing activity during the periods when the wastewater pump was switched off (time between the dashed grey lines in Figure 5a). In contrast, the OPUS could only detect the $\mathrm{H}_{2} \mathrm{~S}$ concentration when a new parcel of dosed wastewater entered the gravity sewer. As for the ISA, there were little to no effects on the $\mathrm{H}_{2} \mathrm{~S}$ concentration during limited and optimal dosing trials. This occurrence exemplifies that the electrochemical sensor (SulfiLogger ${ }^{\mathrm{TM}}$ ) has a higher sensitivity and can detect alternating anaerobic-anoxic conditions in nitrate-dosed sewers.

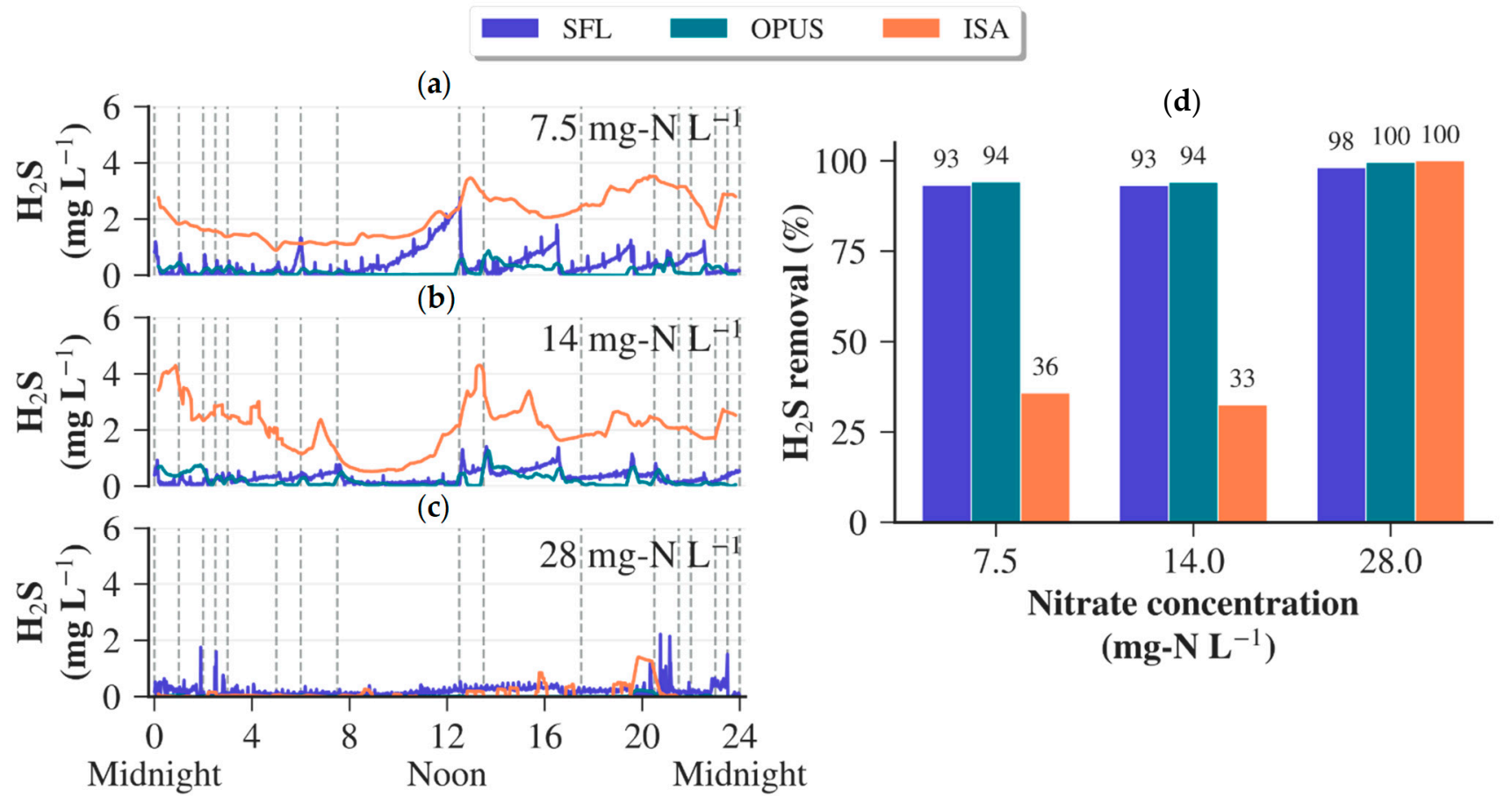

Figure 5. Response of the sensors during calcium nitrate dosing application. $\mathrm{H}_{2} \mathrm{~S}$ profiles measured by the online sensors during limited $\left(7.5 \mathrm{mg}-\mathrm{N} \mathrm{L}^{-1}\right)$, optimal $\left(14 \mathrm{mg}-\mathrm{N} \mathrm{L}^{-1}\right)$, and overdosing scenarios $\left(28 \mathrm{mg}-\mathrm{N} \mathrm{L}^{-1}\right)(\mathbf{a}-\mathrm{c})$. $\mathrm{H}_{2} \mathrm{~S}$ removal percentages for the dosing scenarios (d). Removal percentages calculated using the median $\mathrm{H}_{2} \mathrm{~S}$ concentration obtained during baseline and dosing trials. The vertical dash lines (-) indicate the wastewater pumping periods.

During the nitrate dosing trials, we observed an increase in the sewage $\mathrm{pH}$ ranging from 0.9 to $1.1 \mathrm{pH}$ units for the different dosing scenarios. Without nitrate dosing, the $\mathrm{pH}$ ranged between 6.7-7.6, whereas under dosing conditions, the $\mathrm{pH}$ varied between 7.6-8.7, with a median of 8.4 recorded during the overdosing scenario. As mentioned previously, the $\mathrm{pH}$ increase during nitrate dosing is attributed to both heterotrophic denitrification and anoxic sulfide oxidation [51]. An increased $\mathrm{pH}$ affects the sensors' performance differently. For the UV/Vis sensors (ISA and OPUS), a pH increase favors the detection of the bisulfide ion, which is primarily used to calculate the total dissolved sulfide and hydrogen sulfide [10,52]. For $\mathrm{pH}$ higher than 7, $\mathrm{HS}^{-}$dominates and absorbs at a peak centered around $231 \mathrm{~nm}$ in the UV spectrum [53]. On the other hand, at lower $\mathrm{pH}$ (acidic range), a hyposochromic shift and hypochromic effect occur due to the prevalence of the molecular form $\mathrm{H}_{2} \mathrm{~S}$ [53]. As for the micro-electrochemical sensor (SulfiLogger ${ }^{\mathrm{TM}}$ ), an increase in the sewage $\mathrm{pH}$ means that $\mathrm{H}_{2} \mathrm{~S}$ concentration decreases to a point where the sensor is incapable of detecting $\mathrm{H}_{2} \mathrm{~S}$. According to Jeroschewski et al. 1996 [54], who developed a lab-scaled, micro-electrochemical sensor with similar features to SulfiLogger ${ }^{\mathrm{TM}}$, the protolytic equilibrium limits this type of sensorit is suited for acidic to neutral conditions, but can also be utilized under moderate alkaline conditions $(\mathrm{pH}<8.5)$. Our study found that the increased $\mathrm{pH}$ due to nitrate dosing caused no noticeable effects on the sensors in detecting $\mathrm{H}_{2} \mathrm{~S}$.

The $\mathrm{H}_{2} \mathrm{~S}$ concentrations measured by the ISA during the limited and optimal nitrate dosing concentrations were much higher than the other sensors, as highlighted in the 
$\mathrm{H}_{2} \mathrm{~S}$ profiles (Figure $5 \mathrm{a}, \mathrm{b}$ ). The ISA measurements in these dosing scenarios appeared to be insensitive to nitrate dosing. The key reason for this is that the calibration dataset used for locally calibrating the ISA did not include sulfide measurements under nitrate dosing conditions. In addition, the calibration method used for the ISA did not apply a deconvolution of the bisulfide ion (HS ${ }^{-}$) spectra. Instead, it used a multivariate procedure relating $\mathrm{H}_{2} \mathrm{~S}$ concentrations measured by the reference methods with the measured spectra. Given that the absorption spectra of water samples are a superposition of the absorption spectra of several species, and since both $\mathrm{HS}^{-}$and nitrate have a strong absorbance in the same UV range, deconvolution is required to identify and differentiate the different species [7].

In comparison, the global calibration of OPUS followed the semi-deterministic deconvolution procedure in which a linear substance analysis (curve-fitting) and multiple linear regression analysis were employed to simultaneously detect $\mathrm{HS}^{-}$and nitrate [55]. Meyer et al. 2018 [7] performed a similar calibration for in-situ measurements of nitrate and $\mathrm{H}_{2} \mathrm{~S}$ in the Baltic Sea. In addition, Guitierrez et al. 2010 [14] developed and validated a similar calibration procedure for an online UV/Vis spectrometer to simultaneously measure sulfide and nitrate in sewers for optimizing nitrate dosing for sulfide control. However, the SulfiLogger ${ }^{\mathrm{TM}}$ requires no specific data preprocessing and cumbersome calibration routines as the $\mathrm{H}_{2} \mathrm{~S}$ detection relies on the penetration of $\mathrm{H}_{2} \mathrm{~S}$ through the tip of the sensor and subsequent electrochemical reaction.

To improve the ISA measurements during the nitrate dosing, we recommend performing a new calibration to account for the shift in the composition of the matrix under dosed conditions or adopt the semi-deterministic calibration by decomposition of the spectra.

\subsection{Practical Applications and Challenges}

During its conveyance, wastewater continuously takes part in a series of chemical and microbial processes altering its wastewater composition and matrix during transport. In addition, sewer systems are exposed to highly variable hydraulic conditions [30]. These transformation processes and variable conditions contribute to the dynamic nature of the sulfide problems in sewers. To understand and assess the magnitude of the sewer sulfide problem, $\mathrm{H}_{2} \mathrm{~S}$ sensors are usually installed at identified critical points, e.g., at the end of the pressure sewer. For control measures (e.g., chemical dosing), sensors are installed downstream the point of dosing. It is essential to ensure that the sensors are easily accessible at these monitoring points and can be easily removed for maintenance.

The UV/Vis (ISA and OPUS) sensors are typically installed using a floating or by-pass installation [56]. In addition, orienting the measurement path of the sensors to facilitate the passing of air bubbles formed around the path is essential, as it is known for causing measurement disturbance [57]. Other possible measurement failures of the UV/Vis sensors are typically caused by clogging, accumulation of grease, and carbonate deposits at the measuring path (the lens) of the sensor, even when automatic cleaning using compressed air is carried out. In the case of micro-electrochemical sensors (SulfiLogger ${ }^{\mathrm{TM}}$ ), installation specifications require submerging the sensor's tip in the flowing wastewater while allowing free movement (a pendulum motion) during changes in hydraulic regimes. This pendulumlike motion allows the passage of sanitary solids, such as tissues (wet wipes) occasionally caught at the sensor's tip. During the test trials, we observed that SulfiLogger ${ }^{\mathrm{TM}}$ was sensitive to material accumulation at the installation point (tip of the sensor), resulting in concentration spikes that may not represent the actual $\mathrm{H}_{2} \mathrm{~S}$ concentration in the wastewater. Therefore, continuously examining whether a blockage or an extreme event is responsible for high concentration peaks is required to ensure reliable data. For all sensors evaluated in this study, it is crucial to perform weekly inspection and maintenance routines.

Notification indices or parameters of the measurement quality are vital attributes for assessing the data's reliability during the monitoring period. There is no qualitative index to determine when and how often the signals of the SulfiLogger ${ }^{\mathrm{TM}}$ are affected by disturbances, such as fouling, accumulation of sanitary solids, and other materials at 
the sensor's tip. Therefore, the sensor must be installed to minimize the accumulation of materials at its tip for reliable measurements. As for both the ISA and OPUS, the quality of the spectra, absorbance at specified wavelengths, and light source diagnostics (lamps) can all be used to determine the quality of measurement or series of measurements.

In general, all three sensors can be used and integrated into tools for sewer asset management and the implementation of the real-time chemical control dosing units. However, factors, such as power supply availability and requirements of additional accessories for cleaning, limit the monitoring points' selection. For example, both UV/Vis based sensors require a continuous power supply and air compressor for setting up the automatic cleaning and data transmission to the cloud (remote server) and are therefore only limited to points providing a power source. Of course, battery power supply alternatives can be discussed with the manufacturer, but incur additional costs. For the SulfiLogger ${ }^{\mathrm{TM}}$, the power supply is provided by the PowerCom Box, which produces a battery life of at least 90 days [58]. Furthermore, regarding the European Directives for controlling explosive atmospheres, both the ISA and SulfiLogger ${ }^{\mathrm{TM}}$ are ATEX (ATmospheres EXplosible) certified and can be used in "sensitive" urban spaces.

In terms of these sensors' suitability for optimizing chemical dosing to reduce sulfides in sewers, the results show that all three sensors can be applied to nitrate dosing optimizations applications, even when the sewage $\mathrm{pH}$ is raised above 8 . However, for sulfide control measures that target the release of $\mathrm{H}_{2} \mathrm{~S}$ across the liquid-gas interface, such as $\mathrm{pH}$ elevation (e.g., magnesium hydroxide), it is required to raise the $\mathrm{pH}$ above 9 . Therefore, for these chemical control measures, the SulfiLogger ${ }^{\mathrm{TM}}$ will not be the preferable option. At this $\mathrm{pH}$ level, sulfide detection as total dissolved sulfide may still be possible using UV/Vis sensors; however, the absorbance of polysulfides, which are known to absorb in the UV range, can cause interference [52]. Furthermore, previous experimental trials using ferric nitrate led to the observation that iron sulfide $(\mathrm{FeS})$ precipitates formed during dosing caused discoloration and scratching of the optical lens (Figure S4). Consequently, this led to unreliable measurements and increased maintenance during those trials, highlighting the possible challenges of using UV/Vis spectrometers subjected to iron salt dosing.

Finally, both UV/Vis sensors require $\mathrm{pH}$ probes to convert $\mathrm{HS}^{-}$to the $\mathrm{H}_{2} \mathrm{~S}$ fraction and total dissolved sulfide. However, long-term $\mathrm{pH}$ measurement in sulfide-rich environments is difficult due to the possibility and challenge of sulfide poisoning of the reference electrode [59]. Therefore, to ensure the accuracy of the sulfide monitoring using UV/Vis spectrometers, $\mathrm{pH}$ sensors must be frequently calibrated.

\subsection{Advantages and Disadvantages}

All three sensors share some main advantages; they provide continuous measurements, are monitored online, and do not require chemical agents. Similarly, all three sensors share common disadvantages, such that they all require regular cleaning and maintenance to ensure reliable measurements. From an economic perspective, the SulfiLogger ${ }^{\mathrm{TM}}$ is the least expensive option, with an overall estimated price of $6000 €$ (inclusive of the sensor, PowerCom Box, and installation accessories). Both UV/Vis sensors for sulfide monitoring in sewer systems are around $15,000 €$, as the overall cost entails communication and power boxes, cleaning and installation accessories, and a $\mathrm{pH}$ sensor.

To provide a complete overview of the performance of the online sensors and to guide practitioners and/or researchers engaged in investigations on monitoring sulfide-related processes in sewers systems, we outlined the key advantages and disadvantages of the sensors used in the study in Table 3. 
Table 3. Advantages and disadvantages of the online liquid phase $\mathrm{H}_{2} \mathrm{~S}$ sensors used in the study.

\begin{tabular}{|c|c|c|}
\hline Sensor & Advantages & Disadvantages \\
\hline ISA & $\begin{array}{l}\text { - } \quad \text { Multi-parameter (e.g., } \mathrm{COD}, \mathrm{NO}_{3}-\mathrm{N}, \\
\text { - } \quad \text { Adjustable optical path }(0.5-20 \mathrm{~mm}) \\
\text { - } \quad \text { Includes software for local calibration } \\
\text { - } \quad \text { Measurement quality details (Spectral } \\
\text { - } \quad \text { ATality Index) } \\
\text { - ATEX (ATmospheres EXplosible) certified }\end{array}$ & $\begin{array}{l}\text { Plug-and-measure not available } \\
\text { - } \quad \text { Requires power source-portable power solutions } \\
\text { can be discussed with the manufacturer } \\
\text { Requires additional accessories for continuous } \\
\text { operation, e.g., air compressor automatic cleaning } \\
\text { of the lens } \\
\text { - Not portable } \\
\text { - } \quad \text { Detailed local calibration needs to be computed by } \\
\text { the operator } \\
\text { Requires continuous pH monitoring for conversion } \\
\text { in } \mathrm{H}_{2} \mathrm{~S} \text { and total dissolved sulfide }\end{array}$ \\
\hline OPUS & $\begin{array}{l}\text { Multi-parameter (e.g., } \mathrm{COD}, \mathrm{NO}_{3}-\mathrm{N}, \\
\mathrm{NO}_{2}-\mathrm{N} \text { etc.) } \\
\text { Plug-and-measure (comes with } \\
\text { manufacturer calibration setting) } \\
\text { - Measurement quality details (Spectral } \\
\text { Quality Index } \\
\text { Portable only with an additional purchase } \\
\text { of the G2 -interface box }\end{array}$ & $\begin{array}{l}\text { Requires power source-portable power solutions } \\
\text { can be discussed with the manufacturer } \\
\text { Requires additional accessories for continuous } \\
\text { operation, e.g., air compressor automatic cleaning } \\
\text { of the lens } \\
\text { Only allows simple linear regression local } \\
\text { calibration } \\
\text { - } \quad \text { Detailed local calibration needs to be computed by } \\
\text { the operator } \\
\text { - } \quad \text { Fixed optical path, other lenses are available but } \\
\text { need to purchase separately } \\
\text { Requires continuous pH monitoring for conversion } \\
\text { in } \mathrm{H}_{2} \mathrm{~S} \text { and total dissolved sulfide } \\
\text { Not ATEX certified }\end{array}$ \\
\hline
\end{tabular}

- $\quad$ Plug-and-measure available

- $\mathrm{H}_{2} \mathrm{~S}$ measurements in both liquid and gas phases

- Portable

- Power source provided by a PowerComBox, SulfiLogger ${ }^{\mathrm{TM}}$ providing a battery life up to 90 days

- Quick and straightforward calibration procedure using known $\mathrm{H}_{2} \mathrm{~S}$ gas

- $\quad$ Easy to clean (passive anti-fouling flush front)

- $\quad$ ATEX certified
- $\quad$ Not suitable at $\mathrm{pH}$ values $>8.5$

- Susceptible to blockages at the tip of the sensor requires careful installation

- No details on measurement quality during monitoring

- Only measures $\mathrm{H}_{2} \mathrm{~S}$ (requires a $\mathrm{pH}$ sensor for conversion to total dissolved sulfide)

\section{Conclusions}

Recognizing that liquid phase $\mathrm{H}_{2} \mathrm{~S}$ monitoring is important and offers additional information on the fate of $\mathrm{H}_{2} \mathrm{~S}$ in sewer systems, our study compared three online commercial sensors to shed light on the performance and comparison of these sensors under realistic conditions. Overall, the sensors' comparisons indicate that there are strengths and weaknesses to each sensor used in this study.

For the UV/Vis sensors, the dependency of the calibration procedure, the reference measurements, and the spectra quality used for calibration significantly affect the sensor's performance. The GO ISA UV/Vis spectrometer showed the best agreement with reference measurements $(\mathrm{ECH})$, resulting in a mean bias $(\mathrm{MB})$ of $0.16 \mathrm{mg} \mathrm{L}^{-1}$. However, the ISA responded erroneously to the optimal and limited nitrate dosing test applications as its calibration did not account for nitrate dosing conditions. The global calibration of the TriOS OPUS UV spectrometer overestimated the $\mathrm{H}_{2} \mathrm{~S}$ concentrations, with a mean bias of $-2.48 \mathrm{mg} \mathrm{L}^{-1}$ when compared to the reference method. Contrary to the ISA, the 
OPUS responded to nitrate dosing as expected, as its calibration accounted for the simultaneous detection of nitrate and $\mathrm{H}_{2} \mathrm{~S}$. The micro-electrochemical sensor (SulfiLogger ${ }^{\mathrm{TM}}$ ) showed a good agreement (a mean bias of $0.70 \mathrm{mg} \mathrm{L}^{-1}$ ) with the reference method despite having no pre-requisite calibration procedure involving the reference method. The SulfiLogger ${ }^{\mathrm{TM}}$ exemplified its sensitivity to varying conditions applied during the test applications reasonably.

In retrospect to the findings of this study, the $\mathrm{pH}$ value has a significant influence on the detection of sulfides in sewer systems. Our study showed that the liquid phase $\mathrm{H}_{2} \mathrm{~S}$ sensors measured reliably in sewage $\mathrm{pH}$ varying from 6.7 to 8.7. However, questions concerning the suitability of using the SulfiLogger ${ }^{\mathrm{TM}}$ in applications where the sewage $\mathrm{pH}$ is $>8.5$ should be raised. Similarly, one should question the use of UV/Vis spectrometers for $\mathrm{H}_{2} \mathrm{~S}$ monitoring in applications where the sewage $\mathrm{pH}$ is $<5$. Therefore, further investigations closely examining the influence of $\mathrm{pH}$ on the sensors' response and uncertainty at different $\mathrm{pH}$ levels are required. Finally, regarding our assessment, it is crucial to remember that successful and reliable data collections using these liquid phase $\mathrm{H}_{2} \mathrm{~S}$ sensors depend on local conditions, the means of installation, and the regularity of cleaning and maintenance routines.

Supplementary Materials: The following are available online at https:/ /www.mdpi.com/article/ 10.3390/w13131876/s1, Figure S1: Operation schedule of the wastewater pumps, Table S1: Metrics used for comparing sensor data, Table S2: Summary of the comparison data set (Phase1), Table S3: Summary of the statistical comparison measures applied to the comparison pairs, Figure S2: Target diagram for comparing the reference and sensors' measurements, Table S4: Summary of the statistical distribution measures of the sensors for test applications (Phase 2), Figure S3: Response of nitrate sensors during flow and no flow periods during nitrate dosing application, Figure S4: Possible effect of iron salts dosing application on optical sensors.

Author Contributions: D.D. conceived and designed the experiments; D.D. and M.P.F. performed the experiments; D.D. data analysis and visualization; D.D. and M.P.F. wrote the draft paper; D.D. finalized the paper; all authors edited and revised the paper; M.B.- -supervision. All authors have read and agreed to the published version of the manuscript.

Funding: This work was supported by the German Research Foundation (DFG), Urban Water Interfaces (UWI) Research Training Group (GRK 2032).

Institutional Review Board Statement: Not applicable.

Informed Consent Statement: Not applicable.

Data Availability Statement: The data presented in this study are available upon request from the corresponding author.

Acknowledgments: The authors would like to acknowledge the Berliner Wasserbetriebe (BWB), which permitted the use of the research sewer pilot plant and supported the investigation. In addition, the authors would like to thank the manufactures (TriOS Mess- und Datentechnik GmbH, GO Systemelektronik GmbH, ECH Elektrochemie Halle GmbH, \& SulfiLogger A/S) of the sensors used in the study for providing the sensors and support. Finally, we acknowledge support by the German Research Foundation and the Open Access Publication Fund of TU Berlin.

Conflicts of Interest: The authors declare no conflict of interest. The funders had no role in the design of the study; in the collection, analyzes, or interpretation of data; in the writing of the manuscript, or in the decision to publish the results.

\section{References}

1. Hvitved-Jacobsen, T. Sulfur Transformations in Sewer Networks: Effects, Prediction and Mitigation of Impacts. In Environmental Technologies to Treat Sulfur Pollution: Principles and Engineering, 2nd ed.; Lens, P., Ed.; IWA Publishing: London, UK, 2020; pp. 100-101, ISBN 9781789060966.

2. Haaning Nielsen, A.; Vollertsen, J.; Hvitved-Jacobsen, T. Chemical Sulfide Oxidation of Wastewater-Effects of PH and Temperature. Water Sci. Technol. 2004, 50, 185-192. [CrossRef] 
3. Hvitved-Jacobsen, T.; Vollertsen, J.; Nielsen, A.H. Sewer Processes: Microbial and Chemical Process Engineering of Sewer Networks, 2nd ed.; CRC Press: Boca Raton, FL, USA, 2013; pp. 119-120, ISBN 978-1-4398-8178-1.

4. APHA American Public Health Association. Standard methods for the examination of water and wastewater. In "4500-S ${ }^{2-}$ SULFIDE", Standard Methods for the Examination of Water and Wastewater; APHA-AWWA-WEF: Washington, DC, USA, 2018. [CrossRef]

5. Keller-Lehmann, B.; Corrie, S.; Ravn, R.; Yuan, Z.; Keller, J. Preservation and Simultaneous Analysis of Relevant Soluble Sulfur Species in Sewage Samples. In Proceedings of the Proceedings of 2nd International IWA Conference on Sewer Operation and Maintenance, Vienna, Austria, 26-28 October 2006; Volume 1, pp. 339-346.

6. DIN Deutsches Institut für Normung e.V. German Standard Methods for the Examination of Water, Waste Water and Sludge-Anions (Group D)_Part 27: Determination of Sulfide by Gas Extraction Method (D 27); DIN 384405-D 27:2017-10; Beuth Verlag: Berlin, Germany, 2017.

7. Meyer, D.; Prien, R.D.; Rautmann, L.; Pallentin, M.; Waniek, J.J.; Schulz-Bull, D.E. In Situ Determination of Nitrate and Hydrogen Sulfide in the Baltic Sea Using an Ultraviolet Spectrophotometer. Front. Mar. Sci. 2018, 5. [CrossRef]

8. Miloshova, M.; Baltes, D.; Bychkov, E. New Chalcogenide Glass Chemical Sensors for $\mathrm{S}^{2-}$ and Dissolved $\mathrm{H}_{2} \mathrm{~S}$ Monitoring. Water Sci. Technol. 2003, 47, 135-140. [CrossRef] [PubMed]

9. Shamsipur, M.; Tashkhourian, J.; Sharghi, H. Development of Sulfide-Selective Optode Membranes Based on Immobilization of Methylene Blue on Optically Transparent Triacetylcellulose Film. Instrum. Sci. Technol. 2005, 33, 703-714. [CrossRef]

10. Sutherland-Stacey, L.; Corrie, S.; Neethling, A.; Johnson, I.; Gutierrez, O.; Dexter, R.; Yuan, Z.; Keller, J.; Hamilton, G. Continuous Measurement of Dissolved Sulfide in Sewer Systems. Water Sci. Technol. 2008, 57, 375-381. [CrossRef] [PubMed]

11. Levinn, C.M.; Pluth, M.D. Direct Comparison of Triggering Motifs on Chemiluminescent Probes for Hydrogen Sulfide Detection in Water. Sens. Actuators B Chem. 2021, 329, 129235. [CrossRef]

12. Wang, H.; Li, Y.; Yang, S.; Tian, H.; Liang, S.; Sun, B. Dual-Function Fluorescent Probe for Detection of Hydrogen Sulfide and Water Content in Dimethyl Sulfoxide. ACS Omega 2019, 4, 10695-10701. [CrossRef]

13. Andrich, J.M.S.; Schröder, U. Sulfide Detection by Gold-Amalgam Microelectrodes in Artificial Wastewater. Chemosensors 2020, 8, 49. [CrossRef]

14. Gutierrez, O.; Sutherland-Stacey, L.; Yuan, Z. Simultaneous Online Measurement of Sulfide and Nitrate in Sewers for Nitrate Dosage Optimisation. Water Sci. Technol. 2010, 61, 651-658. [CrossRef]

15. Pacheco Fernández, M.; Knutz, T.; Barjenbruch, M. Multi-Parameter Calibration of a UV/Vis Spectrometer for Online Monitoring of Sewer Systems. Water Sci. Technol. 2020, 82, 927-939. [CrossRef]

16. Despot, D.; Reinhold, L.; Augustyniak, A.; Barjenbruch, M. Dosing Free Nitrous Acid as an Alternative Sulphide Control Technology for Pressure Sewers in Germany. Water 2021, 13, 1015. [CrossRef]

17. Madsen, P.S. Cases. SulfiLogger ${ }^{T M}$ Sensor. Available online: https://sulfilogger.com/cases (accessed on 24 May 2021).

18. Jiang, G.; Sharma, K.R.; Yuan, Z. Effects of Nitrate Dosing on Methanogenic Activity in a Sulfide-Producing Sewer Biofilm Reactor. Water Res. 2013, 47, 1783-1792. [CrossRef] [PubMed]

19. Firer, D.; Friedler, E.; Lahav, O. Control of Sulfide in Sewer Systems by Dosage of Iron Salts: Comparison between Theoretical and Experimental Results, and Practical Implications. Sci. Total Environ. 2008, 392, 145-156. [CrossRef]

20. Stuetz, R.; Frechen, F.B. Odours in Wastewater Treatment-Measurement, Modelling and Control; IWA Publishing: Cornwall, UK, 2005; p. 123, ISBN 978-1-78040-293-2.

21. Manual ISA Spectral Analyzer; GO Systemelektronik GmbH: Kiel, Germany, 2018, Available online: https://www.go-sys.de/en/ downloads (accessed on 20 March 2020).

22. Harris, D.C. Quantitative Chemical Analysis, 8th ed.; W.H. Freeman and Co.: New York, NY, USA, 2010; p. 394, ISBN 978-1-4292-1815-3.

23. TriOS, G. OPUS. Available online: https://www.trios.de/en/opus.html (accessed on 2 February 2021).

24. Maden, P.S. SulfiLogger $\mathrm{H}_{2} \mathrm{~S}$ Sensor. SulfiLogger ${ }^{T M}$ Sensor. Available online: https://sulfilogger.com/sulfilogger-sensor (accessed on 24 May 2021).

25. Yongsiri, C.; Vollertsen, J.; Rasmussen, M.; Hvitved-Jacobsen, T. Air-Water Transfer of Hydrogen Sulfide: An Approach for Application in Sewer Networks. Water Environ. Res. 2004, 76, 81-88. [CrossRef]

26. U.S. Environmental Protection Agency. Design Manual: Odor and Corrosion Control in Sanitary Sewerage Systems and Treatment Plants; U.S. Environmental Protection Agency: Washington, DC, USA, 1985.

27. Sigg, L.; Stumm, W. Aquatische Chemie: Einführung in die Chemie natürlicher Gewässer; 6. Auflage; vdf Hochschulverlag: Zürich, Switzerland, 2016; p. 64, ISBN 978-3-7281-3767-8.

28. Millero, F.J.; Plese, T.; Fernandez, M. The Dissociation of Hydrogen Sulfide in Seawater1. Limnol. Oceanogr. 1988, 33, 269-274. [CrossRef]

29. Hershey, J.P.; Plese, T.; Millero, F.J. The PK1* for the Dissociation of $\mathrm{H}_{2} \mathrm{~S}$ in Various Ionic Media. Geochim. Cosmochim. Acta 1988, 52, 2047-2051. [CrossRef]

30. Brito, R.S.; Pinheiro, H.M.; Ferreira, F.; Matos, J.S.; Lourenço, N.D. In Situ UV-Vis Spectroscopy to Estimate COD and TSS in Wastewater Drainage Systems. Urban Water J. 2013, 11, 261-273. [CrossRef]

31. Borrego, C.; Costa, A.M.; Ginja, J.; Amorim, M.; Coutinho, M.; Karatzas, K.; Sioumis, T.; Katsifarakis, N.; Konstantinidis, K.; De Vito, S.; et al. Assessment of Air Quality Microsensors versus Reference Methods: The EuNetAir Joint Exercise. Atmos. Environ. 2016, 147, 246-263. [CrossRef] 
32. Jolliff, J.K.; Kindle, J.C.; Shulman, I.; Penta, B.; Friedrichs, M.A.M.; Helber, R.; Arnone, R.A. Summary Diagrams for Coupled Hydrodynamic-Ecosystem Model Skill Assessment. J. Mar. Syst. 2009, 76, 64-82. [CrossRef]

33. van Doorn, W.P.T.M. Methcomp: Method Comparison for Clinical Chemistry. 2020. Available online: https://github.com/ wptmdoorn/methcomp (accessed on 1 March 2021).

34. Rochford, P. PeterRochford/SkillMetrics. 2021. Available online: https://github.com/PeterRochford/SkillMetrics (accessed on 1 April 2021).

35. McKinney, W. Data Structures for Statistical Computing in Python. In Proceedings of the 9th Python in Science Conference, Austin, TX, USA, 28 June-3 July 2010; pp. 56-61.

36. Reback, J.; McKinney, W.; Jbrockmendel; Van Den Bossche, J.; Augspurger, T.; Cloud, P.; Hawkins, S.; Gfyoung; Sinhrks; Roeschke, M.; et al. Pandas-Dev/Pandas: Pandas 1.2.4; Zenodo, 2021. Available online: https://zenodo.org/record/4681666\# YLTgmqgzZjU (accessed on 25 April 2021).

37. Harris, C.R.; Millman, K.J.; van der Walt, S.J.; Gommers, R.; Virtanen, P.; Cournapeau, D.; Wieser, E.; Taylor, J.; Berg, S.; Smith, N.J.; et al. Array Programming with NumPy. Nature 2020, 585, 357-362. [CrossRef]

38. Seabold, S.; Perktold, J. Statsmodels: Econometric and Statistical Modeling with Python. In Proceedings of the SciPy 2010 9th Python in Science Conference, Austin, TX, USA, 28-30 June 2010; pp. 92-96.

39. Pedregosa, F.; Varoquaux, G.; Gramfort, A.; Michel, V.; Thirion, B.; Grisel, O.; Blondel, M.; Prettenhofer, P.; Weiss, R.; Dubourg, V.; et al. Scikit-Learn: Machine Learning in Python. J. Mach. Learn. Res. 2011, 12, 2825-2830.

40. Hunter, J.D. Matplotlib: A 2D Graphics Environment. Comput. Sci. Eng. 2007, 9, 90-95. [CrossRef]

41. Waskom, M. Seaborn: Statistical Data Visualization. J. Open Source Softw. 2021, 6, 3021. [CrossRef]

42. Giavarina, D. Understanding Bland Altman Analysis. Biochem. Medica 2015, 25, 141-151. [CrossRef] [PubMed]

43. Watson, P.F.; Petrie, A. Method Agreement Analysis: A Review of Correct Methodology. Theriogenology 2010, 73, 1167-1179. [CrossRef]

44. McBride, G.B. A Proposal for Strength of Agreement Criteria for Lin's Concordance Correlation Coefficient; National Institute of Water \& Atmospheric Research Ltd.: Hamiltonm, New Zealand, 2005, Available online: https:/ /www.medcalc.org/download/pdf/ McBride2005.pdf (accessed on 10 April 2021).

45. Langergraber, G.; Fleischmann, N.; Hofstädter, F. A Multivariate Calibration Procedure for UV/VIS Spectrometric Quantification of Organic Matter and Nitrate in Wastewater. Water Sci. Technol. J. Int. Assoc. Water Pollut. Res. 2003, 47, 63-71. [CrossRef]

46. Rieger, L.; Langergraber, G.; Thomann, M.; Fleischmann, N.; Siegrist, H. Spectral In-Situ Analysis of NO2, NO3, COD, DOC and TSS in the Effluent of a WWTP. Water Sci. Technol. 2004, 50, 143-152. [CrossRef]

47. Lourenço, N.D.; Menezes, J.C.; Pinheiro, H.M.; Diniz, D. Development of PLS Calibration Models from UV-Vis Spectra for TOC Estimation at the Outlet of a Fuel Park Wastewater Treatment Plant. Environ. Technol. 2008, 29, 891-898. [CrossRef]

48. Nielsen, A.H.; Vollertsen, J.; Jensen, H.S.; Madsen, H.I.; Hvitved-Jacobsen, T. Aerobic and Anaerobic Transformations of Sulfide in a Sewer System—Field Study and Model Simulations. Water Environ. Res. 2008, 80, 16-25. [CrossRef]

49. Vollertsen, J.; Revilla, N.; Hvitved-Jacobsen, T.; Nielsen, A.H. Modeling Sulfides, pH and Hydrogen Sulfide Gas in the Sewers of San Francisco. Water Environ. Res. 2015, 87, 1980-1989. [CrossRef]

50. Shypanski, A.H.; Yuan, Z.; Sharma, K. Influence of Pressure Main Pumping Frequency on Sulfide Formation Rates in Sanitary Sewers. Environ. Sci. Water Res. Technol. 2018, 38, 92. [CrossRef]

51. Yang, W.; Vollertsen, J.; Hvitved-Jacobsen, T. Anoxic Sulfide Oxidation in Wastewater of Sewer Networks. Water Sci. Technol. 2005, 52, 191-199. [CrossRef] [PubMed]

52. Guenther, E.A.; Johnson, K.S.; Coale, K.H. Direct Ultraviolet Spectrophotometric Determination of Total Sulfide and Iodide in Natural Waters. Anal. Chem. 2001, 73, 3481-3487. [CrossRef] [PubMed]

53. Pouly, F.; Touraud, E.; Buisson, J.-F.; Thomas, O. An Alternative Method for the Measurement of Mineral Sulphide in Wastewater. Talanta 1999, 50, 737-742. [CrossRef]

54. Jeroschewski, P.; Steuckart, C.; Kühl, M. An Amperometric Microsensor for the Determination of $\mathrm{H}_{2} \mathrm{~S}$ in Aquatic Environments. Anal. Chem. 1996, 68, 4351-4357. [CrossRef]

55. Prien, R.; Meyer, D.; Sadkowiak, B. Optical Measurements of Nitrate and $\mathrm{H}_{2} \mathrm{~S}$ Concentrations in Baltic Waters. In Proceedings of the Oceans 2009-Europe, Bremen, Germany, 11-14 May 2009; pp. 1-5.

56. Gruber, G.; Bertrand-Krajewski, J.-L.; Beneditis, J.D.; Hochedlinger, M.; Lettl, W. Practical Aspects, Experiences and Strategies by Using UV/VIS Sensors for Long-Term Sewer Monitoring. Water Pract. Technol. 2006, 1. [CrossRef]

57. Huebsch, M.; Grimmeisen, F.; Zemann, M.; Fenton, O.; Richards, K.G.; Jordan, P.; Sawarieh, A.; Blum, P.; Goldscheider, N. Technical Note: Field Experiences Using UV/VIS Sensors for High-Resolution Monitoring of Nitrate in Groundwater. Hydrol. Earth Syst. Sci. 2015, 19, 1589-1598. [CrossRef]

58. Madsen, P.S. PowerCom Box. SulfiLogger ${ }^{T M}$ Sensor. Available online: https://sulfilogger.com/powercom-box (accessed on 24 May 2021).

59. Smith Guide to Measuring pH in Challenging Processes. Available online: https://www.watertechonline.com/home/article/14 172589/guide-to-measuring-ph-in-challenging-processes (accessed on 25 May 2021). 